U.S. Geological Survey Wildlife Program

Analyses on Subpopulation Abundance and Annual Number of Maternal Dens for the U.S. Fish and Wildlife Service on Polar Bears (Ursus maritimus) in the Southern Beaufort Sea, Alaska

Open-File Report 2020-1087 



\section{Analyses on Subpopulation Abundance and Annual Number of Maternal Dens for the U.S. Fish and Wildlife Service on Polar Bears (Ursus maritimus) in the Southern Beaufort Sea, Alaska}

By Todd C. Atwood, Jeffrey F. Bromaghin, Vijay P. Patil, George M. Durner, David C. Douglas, and Kristin S. Simac

U.S. Geological Survey Wildlife Program

Open-File Report 2020-1087 


\section{U.S. Department of the Interior \\ DAVID L. BERNHARDT, Secretary}

\section{U.S. Geological Survey James F. Reilly II, Director}

U.S. Geological Survey, Reston, Virginia: 2020

For more information on the USGS-the Federal source for science about the Earth, its natural and living resources, natural hazards, and the environment-visit https://www.usgs.gov/ or call 1-888-ASK-USGS (1-888-275-8747).

For an overview of USGS information products, including maps, imagery, and publications, visit https:/store.usgs.gov.

Any use of trade, firm, or product names is for descriptive purposes only and does not imply endorsement by the U.S. Government.

Although this information product, for the most part, is in the public domain, it also may contain copyrighted materials as noted in the text. Permission to reproduce copyrighted items must be secured from the copyright owner.

Suggested citation:

Atwood, T.C., Bromaghin, J.F., Patil, V.P., Durner, G.M., Douglas, D.C., and Simac, K.S., 2020, Analyses on subpopulation abundance and annual number of maternal dens for the U.S. Fish and Wildlife Service on polar bears (Ursus maritimus) in the southern Beaufort Sea, Alaska: U.S. Geological Survey Open-File Report 2020-1087, 16 p., https://doi.org/10.3133/ofr20201087.

ISSN 2331-1258 (online) 


\section{Contents}

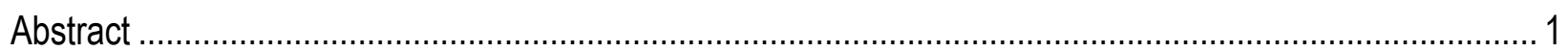

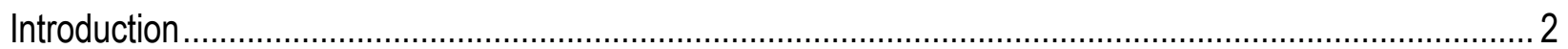

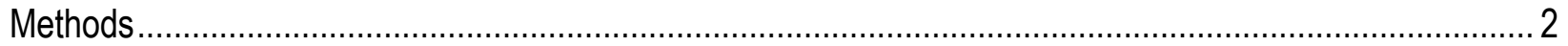

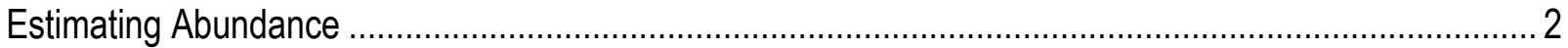

Estimating Number of Terrestrial Dens ..................................................................................... 4

Generating Probability Distributions for Model Parameters ........................................................... 5

Den Abundance Modeling with Uncertainty Propagation ……........................................................

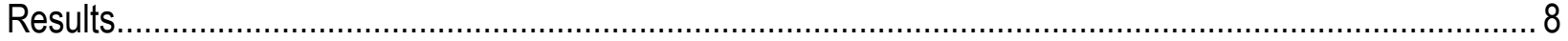

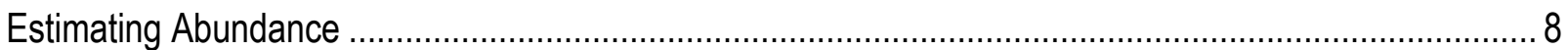

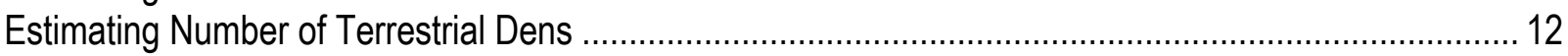

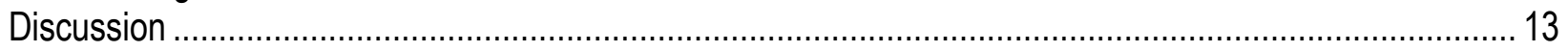

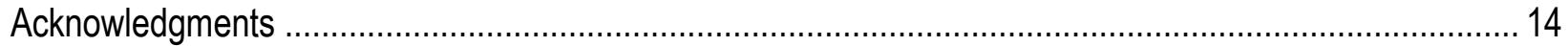

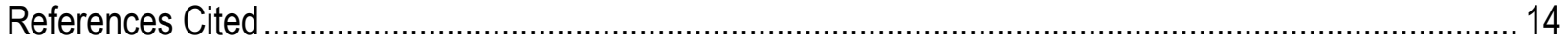

\section{Figures}

1. Map showing southern Beaufort Sea study area with four spatial states (Nearshore-west, Nearshore-east, Offshore-west, and Offshore-east) off the northern coast of Alaska...

2. Map showing distribution of 132 polar bear maternal dens used to calculate the proportions of occurrence on land and in specific regions of northern Alaska.............................................................

3. Graphs showing annual survival rate estimates for polar bears of the Alaska part of the southern Beaufort Sea subpopulation .....

4. Graph showing estimates of the abundance of polar bears in the Alaska part of the southern Beaufort Sea subpopulation

5. Graph showing posterior median estimates of maternal polar bear den abundance by region in the southern Beaufort Sea subpopulation with 95-percent credible intervals, compared to point estimates derived in Wilson and Durner (2020)

\section{Tables}

1. Estimated model parameters (and associated abbreviations) used to calculate polar bear maternal den abundance on the Arctic coastal plain of Alaska.

2. Summary of the combinations of models to estimate survival and recapture probability of southern Beaufort Sea polar bears, showing the number of parameters in the model, the Deviance Information Criterion (DIC) measure of fit, and the difference between each model's DIC and that of the smallest DIC.. 9 


\section{Conversion Factors}

International System of Units to U.S. customary units

\begin{tabular}{lll}
\hline Multiply & By & To obtain \\
\hline & Length & \\
\hline kilometer $(\mathrm{km})$ & 0.6214 & mile $(\mathrm{mi})$ \\
\hline
\end{tabular}

\section{Abbreviations}

$\mathrm{Cl} \quad$ credible interval

CJS Cormack-Jolly-Seber

CtoC Colville to Canning

DIC Deviance information criterion

ESA Endangered Species Act

FWS U.S. Fish and Wildlife Service

IUCN-PBSG International Union for Conservation of Nature Polar Bear Specialist Group

MCMC Markov chain Monte Carlo

MMPA Marine Mammal Protection Act

NPR-A National Petroleum Reserve-Alaska

SBS southern Beaufort Sea

USGS U.S. Geological Survey

VHF very high frequency 


\title{
Analyses on Subpopulation Abundance and Annual Number of Maternal Dens for the U.S. Fish and Wildlife Service on Polar Bears (Ursus maritimus) in the Southern Beaufort Sea, Alaska
}

By Todd C. Atwood, Jeffrey F. Bromaghin, Vijay P. Patil, George M. Durner, David C. Douglas, and Kristin S. Simac

\begin{abstract}
The long-term persistence of polar bears (Ursus maritimus) is threatened by sea-ice loss due to climate change, which is concurrently providing an opportunity in the Arctic for increased anthropogenic activities including natural resource extraction. Mitigating the risk of those activities, which can adversely affect the population dynamics of the southern Beaufort Sea (SBS) subpopulation, is an emerging challenge as polar bears become more reliant on land and come into more frequent contact with humans. The Marine Mammal Protection Act and Endangered Species Act require the U.S. Fish and Wildlife Service to determine whether industrial activities will have a negligible impact on the SBS subpopulation. Information important to making that determination includes estimates of subpopulation abundance and the number of maternal dens likely to be present in areas where industrial activities occur. We analyzed mark-recapture data collected from SBS polar bears sampled in Alaska during 2001-16 using multistate Cormack-Jolly-Seber models. Estimated survival rates were relatively high during 2001-03, lower during 2004-08, then higher during 2009-15 except for 2012. Estimated abundance in the Alaska part of the SBS was consistent with the estimated survival rates, declining from about 1,300 bears in 2003 to 525 bears in 2006 and then remaining generally stable during 2006-15. The point estimate for the Alaska part of the SBS in 2015, the last year in which abundance could be estimated, was 573 bears (95-percent credible interval $=232,1,140$ bears). To estimate the expected number of terrestrial dens likely to be present in a given region in a given year, we used a Bayesian modeling approach based on calculations derived from SBS demographic and denning data. We estimated that the entire SBS subpopulation produced 123 dens per year (median; 95-percent credible interval = 69, 198 dens), 66 (median; 95-percent credible interval $=35,110$ dens) of which were land-based. Most land-based dens were located between the Colville and Canning Rivers (which includes the Prudhoe Bay-Kuparuk industrial footprint), followed by the 1002 Area of the Arctic National Wildlife Refuge and the National Petroleum Reserve-Alaska.
\end{abstract}




\section{Introduction}

Polar bears (Ursus maritimus) rely on sea ice to meet several life history needs, including feeding, mating, and denning (Amstrup, 2003). Loss of sea-ice habitat is the primary threat to their long-term persistence (U.S. Fish and Wildlife Service, 2016). Since 1979, Arctic sea-ice extent and volume in summer have declined at rates of about 14 percent and 27 percent per decade, respectively (Intergovernmental Panel on Climate Change, 2019). In the southern Beaufort Sea (SBS), changes in sea-ice phenology and characteristics have been associated with modifications to polar bear behavior and declines in subpopulation vital rates. For example, as sea ice has become a less-stable substrate for maternal denning, there has been a pronounced shift in the distribution of dens in the SBS from sea ice to land (Fischbach and others, 2007; Olson and others, 2017). As the duration of the open water season (that is, the time period during which sea ice is functionally absent from the biologically productive continental shelf) has increased, so too has the length of time SBS polar bears spend on land during summer and autumn (Schliebe and others, 2008; Atwood, Peacock, and others, 2016). Further, declines in body condition, survival, and abundance have been associated with changes in the availability of sea-ice habitat (Regehr and others, 2010; Rode and others, 2010; Bromaghin and others, 2015). The growing reliance on land by SBS polar bears elevates the importance of mitigating potential disturbances to polar bears denning on the Arctic Coastal Plain of Alaska.

The U.S. Fish and Wildlife Service (FWS) is charged, under the Marine Mammal Protection Act (MMPA) and Endangered Species Act (ESA), with determining whether industrial activities will have a negligible impact on the SBS subpopulation of polar bears. Under the MMPA, the FWS can authorize (through Incidental Take Regulations) the nonlethal, incidental, unintentional take of small numbers of polar bears by harassment if it is determined that such harassment will have a negligible impact on the stock of polar bears and will not have an unmitigable adverse impact on the availability of polar bears for subsistence uses. Similarly, under Section 7 of the ESA, the FWS must make a determination as to whether actions such as industrial activities would jeopardize the continued existence of polar bears or adversely modify or destroy designated critical habitat. Thus, an accurate and current understanding of the population dynamics (particularly survival and abundance) of the SBS subpopulation and the number of maternal dens on the Arctic Coastal Plain of Alaska are needed by the FWS to make negligible impact determinations under the MMPA and jeopardy determinations under the ESA. Here, we provide (1) updated estimates of survival through 2014 and abundance for the Alaska part of the SBS subpopulation from 2002 to 2015, and (2) an estimate of terrestrial maternal dens likely to be present on the Arctic Coastal Plain in a given year.

\section{Methods}

\section{Estimating Abundance}

Aircraft were used to search for bears on the sea ice between the U.S.-Canada border $\left(141^{\circ} \mathrm{W}\right)$ and about $158.5^{\circ} \mathrm{W}$ from late-March to mid-May each year during 2001-16. Once a bear was sighted in terrain in which it was safe to sample, it was (1) anesthetized and captured, (2) or "biopsy darted" to obtain a tissue sample without capture to determine individual identity using genetics, or (3) recognized from a previous capture and its observation was recorded. Newly captured polar bears were given a unique numeric tattoo on the buccal cavity side of both 
upper lips and a numbered plastic ear tag in both ear pinnae. Beginning in 2013, a microchip with a unique numeric code was injected subcutaneously behind either the right or left ear pinna. Depending on research objectives each year, some bears may have been fitted with various telemetry devices that allowed their locations to be monitored by satellite or to be remotely identified when observed during aircraft search operations.

We used multistate Cormack-Jolly-Seber (CJS) models (similar to Lebreton and Pradel, 2002) to estimate annual survival probabilities and abundance. The area in which captures have historically occurred (hereinafter the study area) was partitioned into four spatial states:

(1) Nearshore-west, (2) Nearshore-east, (3) Offshore-west, and (4) Offshore-east (fig. 1). The division between west and east states was selected as longitude $151^{\circ} \mathrm{W}$, a region in which relatively few captures have occurred historically. The division between nearshore and offshore was selected as the 67 th percentile of aircraft distances from the mainland coast while searching for bears $(43.246 \mathrm{~km})$. Although divisions based on the 50th and 80th percentiles were evaluated, the division based on the 67 th percentile produced states that balanced variation in effort with sufficient numbers of captures for numerical stability. The two offshore states extended outward to $104.606 \mathrm{~km}$, a distance equal to the 99.5 th percentile of aircraft distances from the coast and that encompassed all capture locations. The area outside these four spatial states was considered a fifth spatial state termed "Elsewhere." A sixth non-spatial state was used to absorb modeled mortality. This multistate design allowed us to explicitly incorporate information on the spatial distributions of polar bears and aircraft search efforts in population models and was expected to provide an effective means of accommodating heterogeneity in recapture probabilities.

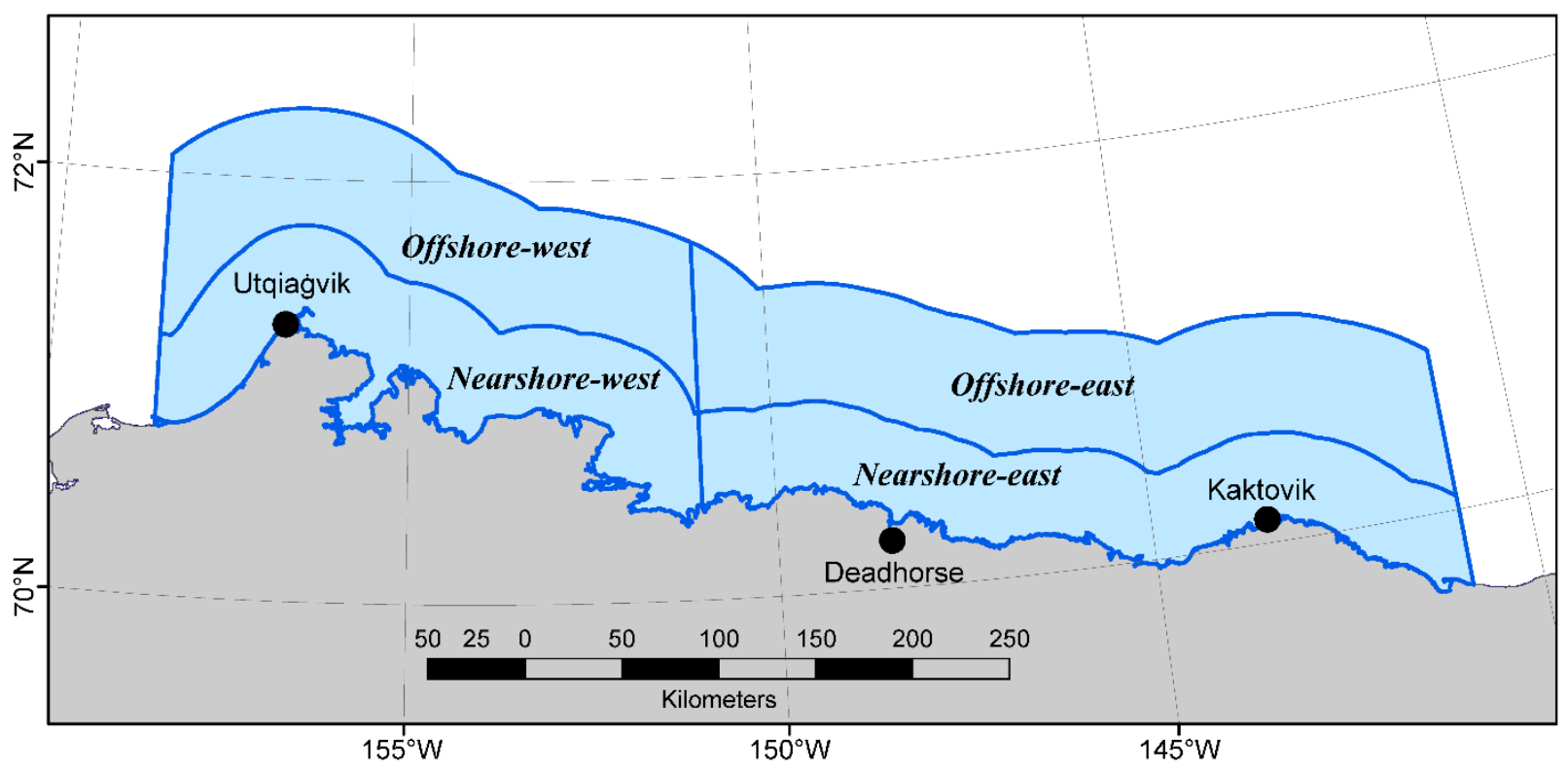

Figure 1. Southern Beaufort Sea study area with four spatial states (Nearshore-west, Nearshore-east, Offshore-west, and Offshore-east) off the northern coast of Alaska.

Multistate CJS models used traditional mark-recapture observations as well as location data from telemetered bears and aircraft flight tracks while searching for bears (Bromaghin and others, 2020). The location of each mark-recapture observation was assigned to the spatial state in which it occurred. Similarly, each telemetered bear was first classified as being in or out of the study area based on most of its location data each spring. Bears classified as being within the 
study area were then assigned to the spatial state within the study area in which the highest number of their locations occurred. Search efforts within each spatial state were quantified by the distance flown while searching for bears.

Multistate CJS models had component submodels for survival, state-transition, and recapture probabilities. Survival probabilities varied by age-class, sex, and time. We used six age classes: (1) Age0 (cubs of the year), (2) Age1 (yearlings), (3) Age2 (first year independent), (4) Ages3-4 (subadults), (5) Ages5-19 (adults), and (6) Age20+ (old adults); the survival of individuals of unknown age was computed as a weighted average of survival for the Ages3-4, Ages5-19, and Age20+ age classes. Two structures for time were considered, one with time as an additive factor and the other with time partially interacted with age-class. With the additive structure (Sex + Age + Time), the survival of all sex and age classes varied in concert through time with a parameter for each year, parallel on the logit scale. The partially interacted time structure (Sex + Age*Time) was similar, but Age0 and Age2 individuals each had time parameters independent of those from the other age classes. State-transition probabilities were equal for all individuals and constant through time, with individuals having a probability of remaining in their current state or transitioning to one of the other states. Recapture probabilities varied as a function of the spatial state occupied and either the distance flown within each state each year (Distance) or time. When recapture probabilities varied through time, the probabilities in the four spatial states within the study area varied in concert through time, being parallel on the logit scale.

Parameters were estimated using Bayesian methods in R version 3.6.3 (R Core Team, 2020) as implemented in the packages rjags (Plummer, 2019) and jagsUI (Kellner, 2019). All prior distributions were uninformative, being uniformly distributed over suitably broad numeric support. State occupancies were known for marked bears in the years they were captured and were otherwise modeled using survival and state-transition probabilities. Recapture probabilities were used to model the binomial outcome of whether or not a bear was observed, conditioned on the state it occupied with no probability of recapture for individuals in the Elsewhere state. Abundance in each year was estimated using the Horvitz-Thompson estimator (Horvitz and Thompson, 1952; McDonald and Amstrup, 2001). State occupancies of telemetered bears were modeled using the same state-transition probabilities as the mark-recapture bears between the first and last years in which they contributed data; they were alive during this period so their survival was not modeled and their data informed state-transition probabilities only. For each model, five Markov chains were initialized with random starting points and a burn-in of 200,000 iterations, and then run for 100,000 iterations with a thinning rate of 25 (to reduce serial correlation in the samples to support work planned for the future), resulting in a posterior sample size of 20,000. Convergence was assessed using the Gelman-Rubin convergence diagnostic $\mathrm{R}_{c}$, with values less than 1.1 consistent with convergence (Gelman and Rubin, 1992), and by examining Markov chain trace plots for signs of inadequate mixing.

\section{Estimating Number of Terrestrial Dens}

We estimated the number of maternal polar bear dens (with associated uncertainty) in any given contemporary year in the SBS subpopulation on land and within the boundaries of the 1002 Area (hereinafter 1002) of the Arctic National Wildlife Refuge, the National Petroleum Reserve-Alaska (NPR-A), the region between the Colville and Canning Rivers (CtoC), and all other terrestrial regions (Other). The $\mathrm{CtoC}$ area includes the Prudhoe Bay and Kuparuk oil fields. We used a Bayesian modeling approach to estimate the expected number of dens in each 
geographic region per year. This model was based on calculations outlined in Wilson and Durner (2020) but expanded to incorporate estimates of parameter uncertainty and to generate estimates of den abundance for the four regions. Model parameters used in the calculation of regional maternal den abundance and their abbreviations are listed in table 1.

Table 1. Estimated model parameters (and associated abbreviations) used to calculate polar bear maternal den abundance on the Arctic Coastal Plain of Alaska.

\begin{tabular}{ll}
\hline \multicolumn{1}{c}{ Parameter } & Abbreviation \\
\hline Number of polar bears in the southern Beaufort Sea subpopulation & Nbears \\
Proportion of adult females with cubs of the year & pAFC0 \\
Proportion of successful dens & pDensuccess \\
Proportion of dens on land & pLand \\
Proportion of land-based dens within the 1002 Area & p1002 \\
Proportion of land-based dens within the National Petroleum Reserve-Alaska & pNPR-A \\
Proportion of land-based dens between the Colville and Canning Rivers & pCtoC \\
Proportion of land-based dens in other locations & pOther \\
\hline
\end{tabular}

\section{Generating Probability Distributions for Model Parameters}

The number of bears (Nbears) was modeled as a normal distribution with a mean of 908 bears and a standard deviation of 163.8 bears, based on a reported 2010 SBS subpopulation abundance estimate and associated 90-percent confidence interval (Bromaghin and others, 2015). These abundance and variance estimates represented the entire SBS subpopulation, as encompassed by the population boundary recognized by the International Union for Conservation of Nature Polar Bear Specialist Group (IUCN-PBSG) as of 2015 (International Union for Conservation of Nature-Polar Bear Specialist Group, 2017). The standard deviation was derived from confidence interval bounds using the rriskDistributions package in $\mathrm{R}$ (R Core Team 2019; Belgorodski and others, 2017).

For all other parameters in table 1, we derived an appropriate probability distribution based on inter-annual variation in polar bear capture data and denning observations. Observed proportions in the input data for each year $i$ were treated as the result of random draws from binomial or multinomial processes (eq. 1). The notation $\mathrm{A}_{i} \sim \operatorname{dist}($ parameter $1=\ldots$, parameter 2 $=\ldots$ ) indicates that the observed quantity $\mathrm{A}$ in year $i$ was modeled as a random draw from the probability distribution dist and its associated parameters.

For each year $i$ :

$$
\begin{aligned}
& \text { NAFC0_obs } i \sim \operatorname{binomial}(\mathrm{p}=\mathrm{pAFC} 0, \mathrm{n}=\text { Nbears_obs } i) \\
& \text { Ndens_success_Rode } i \sim \operatorname{binomial}(\mathrm{p}=\mathrm{pDensuccess}, \mathrm{n}=\text { Ndens_obs_Rode } i) \\
& \text { Land-based dens_obs } i \sim \operatorname{binomial}(\mathrm{p}=\mathrm{pLand}, \mathrm{n}=\text { Ndens_obs } i) \\
& {\left[1002 \_o b s i, \mathrm{NPR}-\mathrm{A} \_ \text {_obs } i, \mathrm{CtoC} \_\mathrm{obs} i, \text { Other_obs } i\right]} \\
& \sim \text { multinomial }(\mathrm{p}=[\mathrm{p} 1002, \mathrm{pNPR}-\mathrm{A}, \mathrm{pCtoC}, \mathrm{pOther}], \mathrm{n}=\text { Ldens_obs } i) .
\end{aligned}
$$


The number of observed dens and captured bears in each category in each year $i$ was known based on input data, whereas the associated probabilities were unknown and were estimated by the model. Nbears_obs $i$ and NAFC0_obs $i$ were the total number of captured bears and the number of captured adult females ( $>4$ years old) with cubs of the year in each year $i$ during 2001-10 (Bromaghin and others, 2015). Ndens_success_Rode $i$ and Ndens_obs_Rode $i$ were the number of successful dens and the total number of dens in each year $i$ during 2001-05 and 2007-10, as reported by Rode and others (2018). Finally, we used a maternal den catalogue (Durner and others, 2020) to quantify variation in the proportion of maternal dens (measured yearly quantities were distinguished with " $i$ " subscripts) within each study area among years. Years prior to 2000 were excluded to reduce potential bias due to temporal trends on the proportion of dens on land. We further restricted den records to include only those from bears whose radio tag deployment was within the bounds of the SBS subpopulation and dens that were detected using satellite or very high frequency (VHF) radio tags. This yielded 132 dens that fit all criteria for inclusion. We then classified dens as land-based or sea-ice and assigned landbased dens to individual study areas by overlaying den coordinates with a map of study area boundaries (fig. 2) using the rgeos package in R (Bivand and Rundel, 2019). A total of 71 dens were found on land, of which there were 15 in the 1002, 12 in the NPR-A, 31 in CtoC, and 13 from elsewhere (Other). A total of 61 dens were found on the sea ice. For each year $i$ with available data from 2000-15, we calculated the total number of SBS dens detected by satellite or VHF tag (Ndens_obs $i$ ), the number of dens detected on land (Land-based dens_obs $i$ ) and the number of land-based dens occurring within the 1002 (1002_obsi), the NPR-A (NPR-A_obsi), and the region between the Colville and Canning Rivers (CtoC_obsi). 


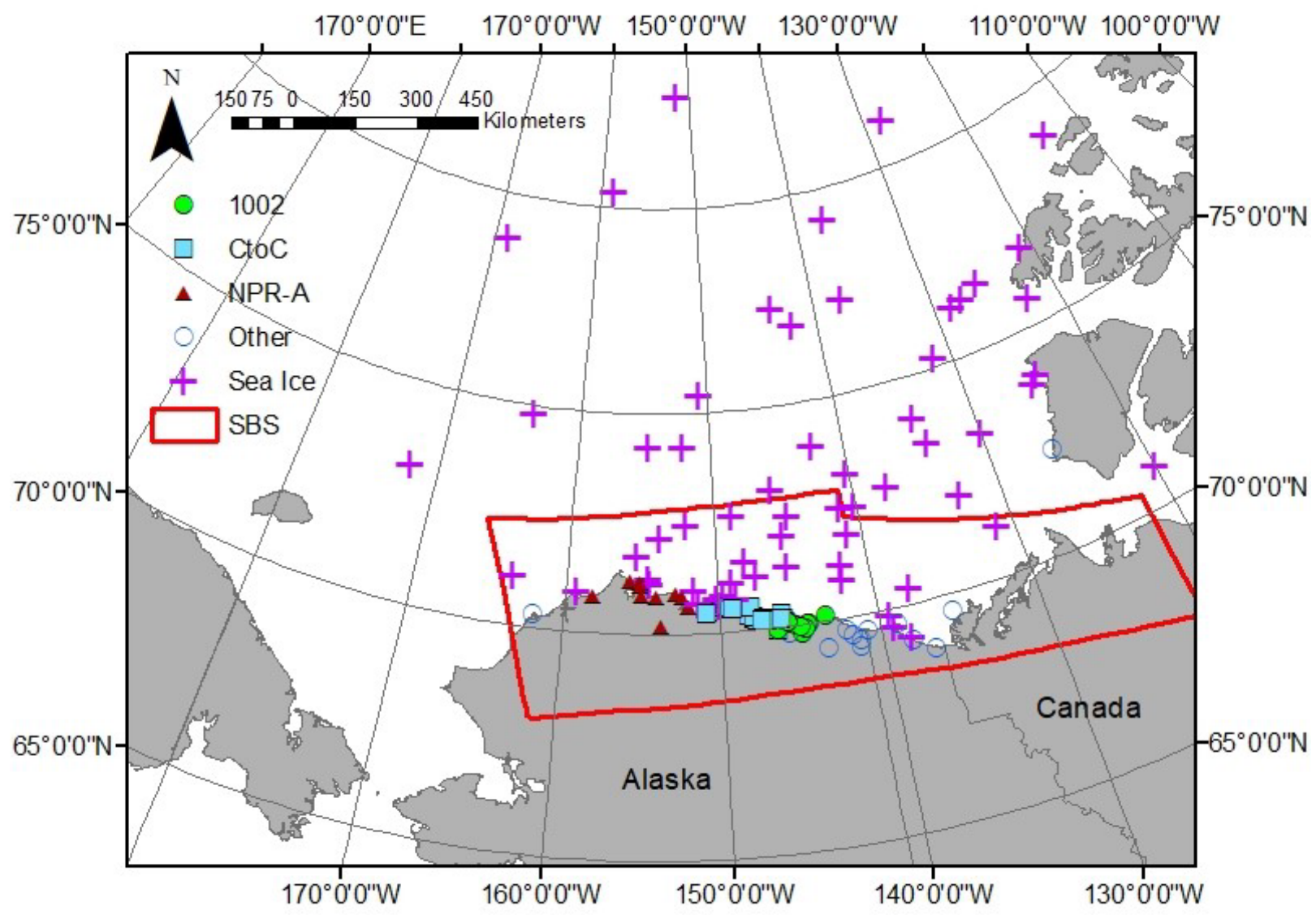

Figure 2. Distribution of 132 polar bear maternal dens used to calculate proportion of occurrence on land and in specific regions of northern Alaska. Den locations were obtained from Durner and others (2020) for bears that were captured within the southern Beaufort Sea (SBS) subpopulation (red polygon based on the International Union for Conservation of Nature Polar Bear Specialist Group boundary [International Union for Conservation of Nature-Polar Bear Specialist Group, 2017]). Dens are coded based on location: The 1002 Area of the Arctic National Wildlife Refuge (1002), the National Petroleum Reserve-Alaska (NPR-A), between the Colville and Canning Rivers (CtoC), sea-ice dens, and land-based dens in other locations (Other).

\section{Den Abundance Modeling with Uncertainty Propagation}

After estimating probability distributions for all parameters, a posterior distribution for the expected number of dens in each region of the SBS could be computed by Markov chain Monte Carlo (MCMC) methods. First, the number of adult females with cubs was estimated from a binomial process (eq. 2):

Nbears $\sim \operatorname{Normal}($ mean $=908, \sigma=163.8)$

Number of adult females with cubs $\sim \operatorname{binomial}(\mathrm{p}=\mathrm{pAFC} 0, \mathrm{n}=$ Nbears $)$. 
Second, the number of failed dens (no cub emergence or complete litter loss within 100 days of emergence) was modeled as a negative binomial process (eq. 3). Third, failed and successful dens were summed to determine the expected number of total dens (eq. 3):

Number of failed dens $\sim$ negative binomial(pDensuccess, Number of adult females with cubs)

Number of dens $($ total $)=$ Number of failed dens + Number of adult females with cubs .

Finally, the number of land-based dens was modeled as a binomial process, and the distribution of land-based dens was modeled as a multinomial process (eq. 4):

Number of dens on land $\sim \operatorname{binomial}(\mathrm{p}=\mathrm{pLand}, \mathrm{n}=$ Number of dens (total $)$ )

Number of dens in each region[1002, NPR-A, CtoC, Other]

multinomial $(\mathrm{p}=$ [p1002, pNPR-A, $\mathrm{pCtoC}, \mathrm{pOther}], \mathrm{n}=$ Number of dens on land $)$.

This approach allowed us to account for uncertainty associated with each parameter and propagate that uncertainty through all downstream calculations. We ran the model for 50,000 iterations, discarding the first 5,000 iterations as a burn-in period. We evaluated model convergence based on the degree of mixing among three MCMC chains. We ran models in Jags version 3.2.0 (Plummer, 2012) called from R using the packages rjags (Plummer, 2019) and jagsUI (Kellner, 2019). Model convergence was assessed based on the Gelman-Rubin statistic $R_{c}$ (Gelman and Rubin 1992).

\section{Results}

\section{Estimating Abundance}

The mark-recapture data comprised 1,224 observations of 868 individual bears. The number of years in which individual bears were observed ranged from 1 to $8 ; 75.7$ percent were only observed once, similar to what Bromaghin and others (2015) reported. The number of bears observed each year ranged from 124 in 2004 to 21 in 2016 and averaged 77. A total of 122 telemetered bears provided location data during at least two capture seasons.

The multistate CJS model with additive time structure in both survival and recapture probability provided the most parsimonious fit to the data (table 2), as measured by the Deviance Information Criterion (DIC; Spiegelhalter and others, 2014), and was selected as the top model. Because both survival and recapture probabilities vary through time, they are confounded in the last year of the study and their values cannot be separately estimated. The maximum value of the Gelman-Rubin statistic $\mathrm{R}_{\mathrm{c}}$ was 1.066 among all parameters and 1.006 when parameters associated with the last year of the study were excluded. The Markov chains looked well-mixed in all trace plots (not shown). 
Table 2. Summary of the combinations of models to estimate survival and recapture probability of southern Beaufort Sea polar bears, showing the number of parameters in the model (NP), the Deviance Information Criterion (DIC) measure of fit, and the difference $(\Delta)$ between each model's DIC and that of the smallest DIC.

\begin{tabular}{llccc}
\hline \multicolumn{1}{c}{ Survival } & \multicolumn{1}{c}{ Recapture } & NP & DIC & $\Delta$ DIC \\
\hline Sex + Age + Time & State + Time & 61 & 5553.0 & 0 \\
Sex + Age*Time & State + Distance & 80 & 5565.4 & 12.4 \\
Sex + Age + Time & State + Distance & 52 & 5571.5 & 18.5 \\
Sex + Age*Time & State + Time & 89 & 5611.4 & 58.1 \\
\hline
\end{tabular}

Estimated survival rates from 2001-09 were similar to those of Bromaghin and others (2015; fig. 3), who discuss the environmental and ecological conditions that might have led to reduced survival. In general, survival rates were relatively high during 2001-03, lower during 2004-08, and then higher in 2009. Beyond 2009, our findings suggest that higher survival rates persisted through 2015, except in 2012. The Ages5-19 age-class had the highest survival rate and the Age 0 age-class had the lowest survival rate. 


\section{Sex M Male 币 Female}
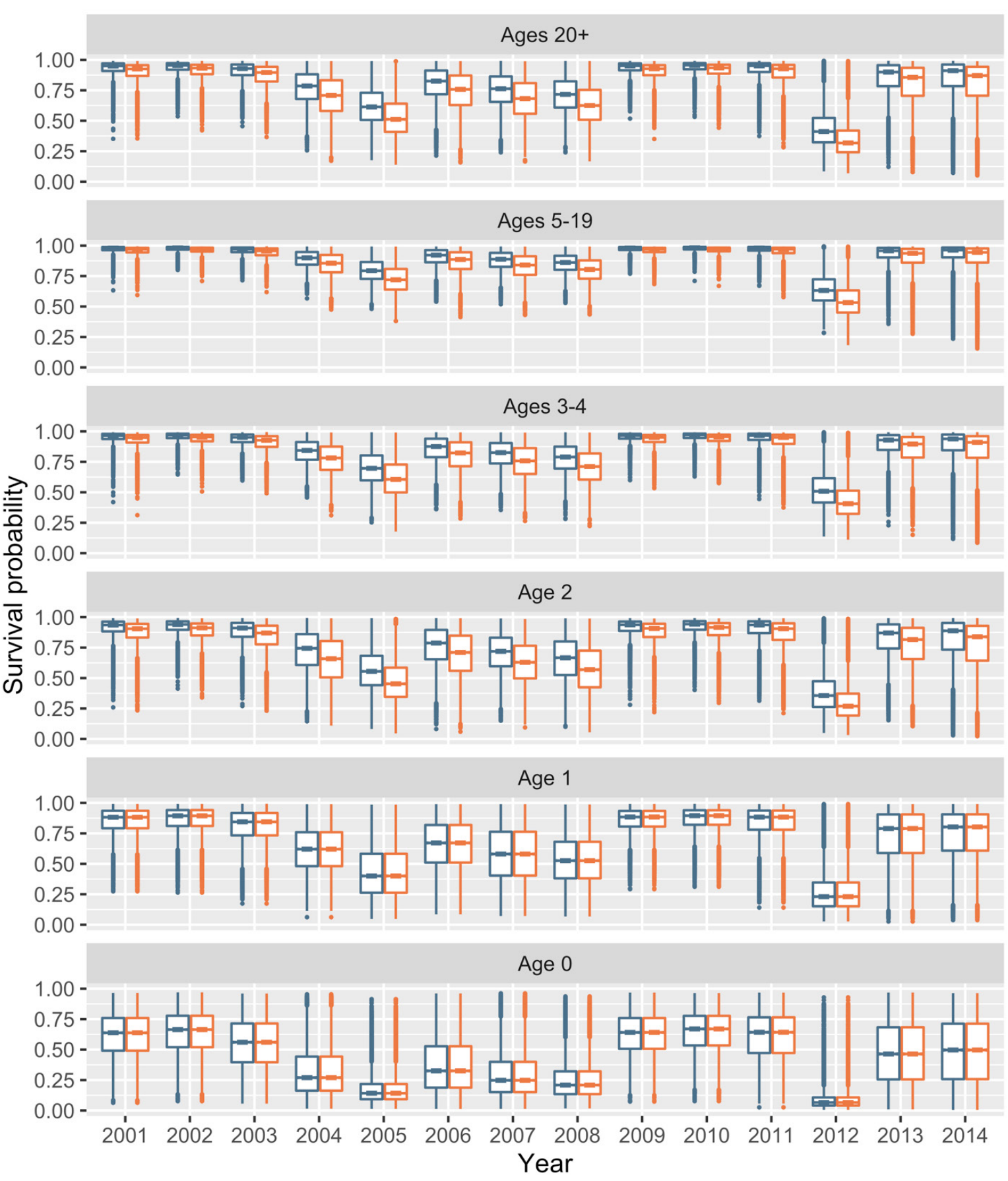

Figure 3. Annual survival rate estimates for polar bears of the Alaska part of the southern Beaufort Sea subpopulation. Each boxplot is based on a sample of 20,000 survival rates drawn from the posterior distribution for a specific combination of age class, sex, and year. The line in the middle of each "box" is the median, the lower and upper extents of each box are the 25th and 75th quartiles, and the "whiskers" extend to the most extreme values that are no more than 1.5 times the box width below or above the 25th and 75 th quartiles, respectively, with any more extreme values plotted individually. Survival rates pertain to the spring of the indicated year to the spring of the subsequent year. 
The pattern in abundance estimates (fig. 4) was consistent with the estimated survival rates (fig. 3) and similar to the findings of Bromaghin and others (2015) during 2001-10. Estimated abundance in the Alaska part of the SBS declined significantly during 2003-06, years in which survival was estimated to be low. Abundance estimates generally were stable during 2006-15. The estimates hint that abundance may have been increasing during 2009-12, after which a year of low survival may have largely offset those gains. The point estimate and 95percent credible interval (CI) in 2010, the last year reported in the prior analysis (Bromaghin and others, 2015), were 562 and $(363,873)$, respectively. For 2015, the last year in this study, abundance and 95-percent CI were 573 and $(232,1,140)$, respectively; note the increased uncertainty of the abundance estimate for the last year. From 2006 to 2015, during which abundance estimates fluctuated but generally were stable, the average estimated abundance and 95-percent CI were 565 and $(340,920)$, respectively.

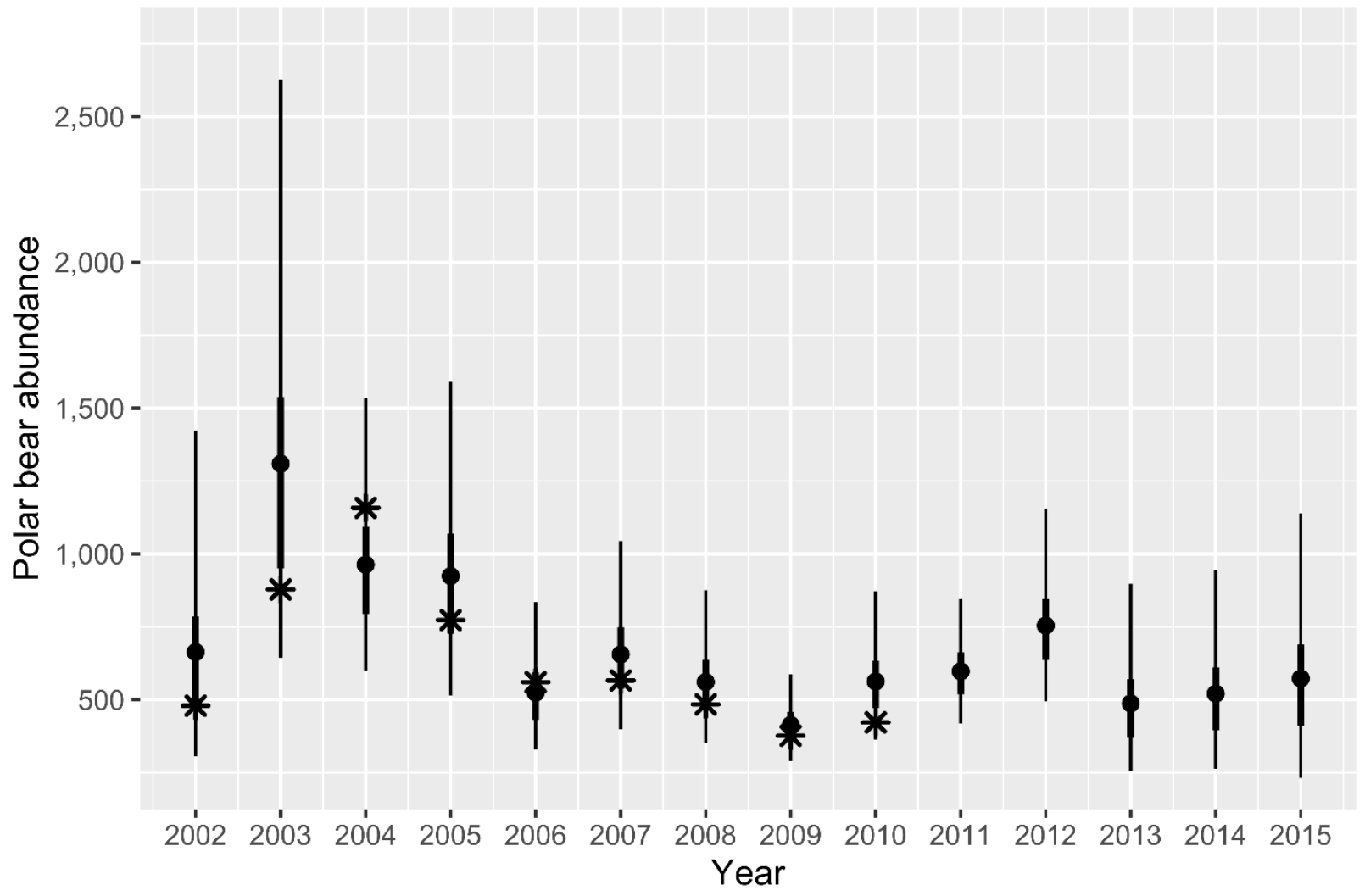

Figure 4. Estimates of the abundance of polar bears in the Alaska part of the southern Beaufort Sea subpopulation. The black symbol is the mean, the heavy black line is the 50-percent credible interval $(\mathrm{Cl})$, and the thin black line is the 95-percent $\mathrm{Cl}$, all based on 20,000 samples from the posterior distribution of abundance in each year. The asterisk points are the point estimates reported by Bromaghin and others (2015).

The 2002 abundance estimate is known to be biased low (Bromaghin and others, 2015) because no capture effort was based out of Utqiağvik in 2001, and 2002 was the first year that marked bears were released in all parts of the study area. Accordingly, the first admissible abundance estimate is for 2003. Additionally, Bromaghin and others (2015) reported evidence that bear movement into and out of the study area may not be Markovian. The existence of non- 
Markovian movement implies that some time was needed for marked and unmarked bears to mix, which provides additional evidence that the 2002 abundance is likely to be negatively biased. Additional work to investigate the influence of bear movement on abundance estimates is underway.

The part of the SBS subpopulation off the Alaska coast is a large subset of the entire subpopulation and it seems reasonable to assume that estimates of demographic parameters based on U.S. Geological Survey (USGS) Alaska data are informative with respect to the entire subpopulation. The abundance estimates of Bromaghin and others (2015) derived from USGS Alaska data averaged 65 percent of the estimates for the whole subpopulation derived from USGS and Canadian data. Those estimates were based on data using the IUCN-PBSGrecognized eastern boundary of the SBS subpopulation of $125^{\circ} \mathrm{W}$. Based on that boundary, 60.5 percent of the SBS area occurs west of the Alaska-Canada border. However, Canadian biologists and co-management authorities are now using an eastern boundary of $133^{\circ} \mathrm{W}$ and, under that definition, 77.8 percent of the total SBS area is in Alaska.

\section{Estimating Number of Terrestrial Dens}

We estimated that the SBS polar bear subpopulation produced 123 dens per year (median), with a 95-percent CI ranging from 69 to 198 dens (fig. 5). The posterior median number of land-based dens in the SBS was 66 (95-percent CI $=35,110)$ (fig. 5). Within the Arctic Coastal Plain, the posterior median number of dens in the 1002 was 14 (95-percent CI $=5$, $30)$, with 12 dens in the NPR-A $(95$-percent $\mathrm{CI}=3,26)$ and 26 dens between the Colville and Canning Rivers (95-percent $\mathrm{CI}=11,48$ ) (fig. 5). In comparison, Wilson and Durner (2020) derived a point estimate of 153 dens per year, of which 85 occurred on land and 19.5 occurred within the 1002. All point estimates of den abundance from Wilson and Durner (2020) fell within the 95-percent posterior credible intervals from this analysis (fig. 5). $\mathrm{R}_{\mathrm{c}}$ was less than 1.1 for all parameters, indicating adequate convergence of the den abundance model. 


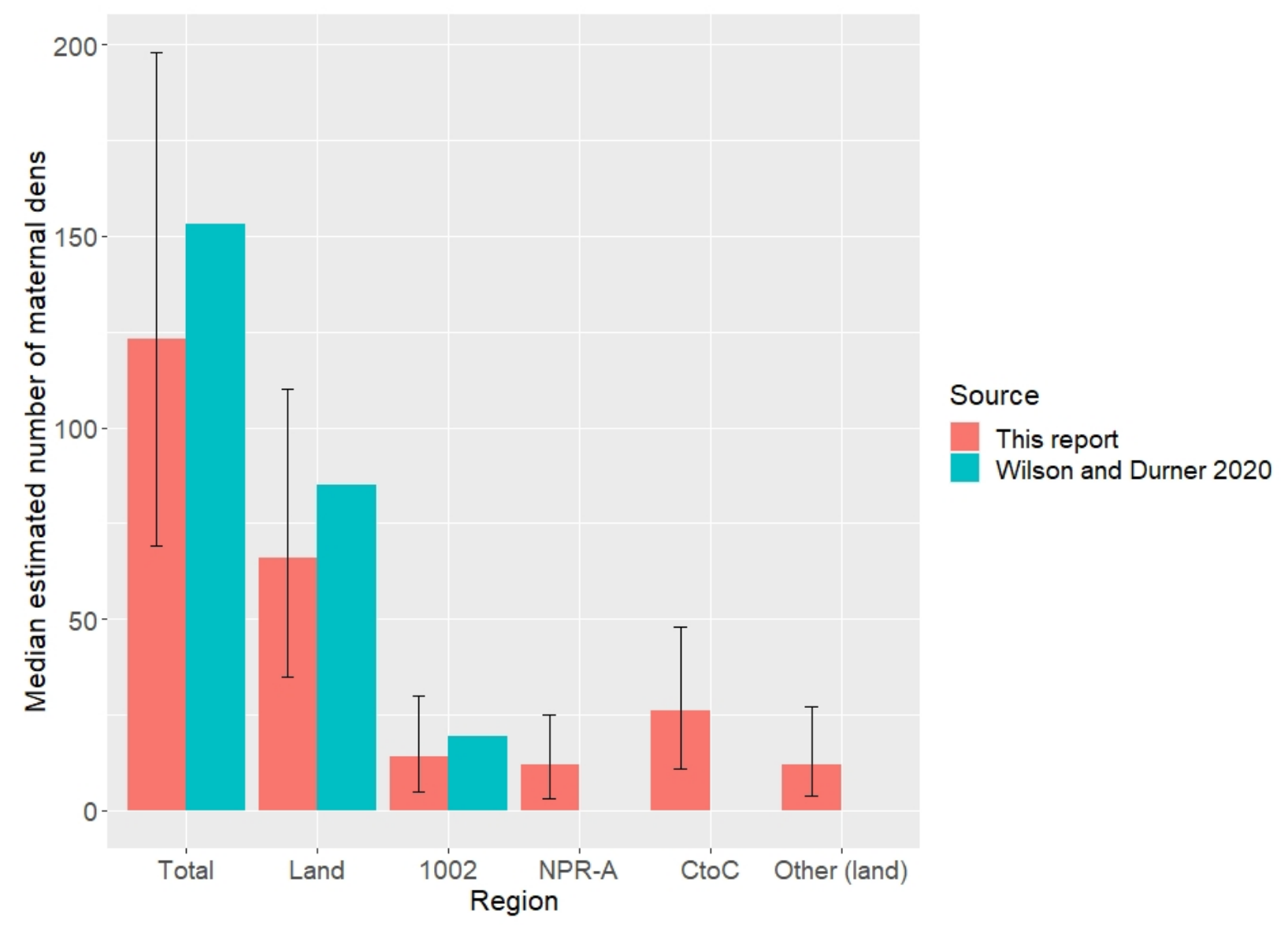

Figure 5. Posterior median estimates of maternal polar bear den abundance by region in the southern Beaufort Sea subpopulation, with 95-percent credible intervals, compared to point estimates derived in Wilson and Durner (2020). Den estimates are shown for the entire southern Beaufort Sea subpopulation (Total), land-based dens (Land), and dens in the Arctic National Wildlife Refuge 1002 Area (1002), the National Petroleum Reserve-Alaska (NPR-A), between the Colville and Canning Rivers (CtoC), and other locations (Other).

\section{Discussion}

The estimated survival rates of southern Beaufort Sea (SBS) polar bears declined in the mid-2000s, increased in the late 2000s, and then remained mostly stable in the 2010s (that is, 2010-15). Estimated survival rates during 2001-09 and abundance estimates during 2002-10 were similar to those reported for the Alaska part of the study area from the previous markrecapture analyses (Bromaghin and others, 2015). Collectively, these findings suggest that the abundance of the SBS subpopulation has remained relatively stable since the decline that occurred in the mid-2000s. The eastern boundary of the SBS subpopulation was shifted to the west in 2014, which increased the percentage of the subpopulation area that occurs in Alaska from 60.5 to 77.8 percent. Accordingly, abundance and survival rate estimates derived from bears sampled in Alaska should serve as a robust index for survival rates and abundance of the entire subpopulation. 
Our point estimates of the total numbers of dens, land-based dens, and dens within the 1002 Area (1002) were not notably dissimilar from those derived by Wilson and Durner (2020). We estimated that the median number of land-based dens occurring in the SBS in a given year was 66, with most of those likely to occur between the Canning and Colville Rivers, followed by the 1002 and the National Petroleum Reserve-Alaska. More than 60 percent of pregnant female polar bears from the SBS subpopulation now den on land, which is a 50-percent increase in the frequency of land-based denning since the 1980s (Fischbach and others, 2007; Olson and others, 2017). As sea ice becomes a less stable substrate in winter, the frequency of land-based denning by SBS polar bears likely will continue to increase.

\section{Acknowledgments}

We thank J. Pearce (U.S. Geological Survey [USGS]), R. Russell (USGS), D. Koons (Colorado State University), R. Suydam and A. Von Duyke (North Slope Borough-Department of Wildlife Management), and G. Givens (Givens Statistical Solutions) for thoughtful comments that improved the quality of this report. We thank the U.S. Fish and Wildlife Service, Bureau of Land Management, and industry for the support and assistance provided over the years. We thank the North Slope Borough-Department of Wildlife Management, Alaska Nanuuq Commission, and Alaska Nannut Co-Management Council for many thoughtful discussions on polar bear ecology. This report was reviewed and approved by the USGS under its Fundamental Science Practices policy (https://www.usgs.gov/fsp).

\section{References Cited}

Amstrup, S.C., 2003, Polar Bear (Ursus maritimus), in Feldhamer, G.A., Thompson, B.C., and Chapman, J.A., eds., Mammals of North America-Biology, management, and conservation: Baltimore, Maryland, John Hopkins University Press, p. 587-610.

Atwood T.C., Peacock, E.L., McKinney, M.A., Lillie, K., Wilson, R.R., Douglas, D.C., Terletzky, P., and Miller, S., 2016, Rapid environmental change drives increased land use by an Arctic marine predator: PLoS ONE, v. 11, p. e0155932.

Belgorodski, N., Greiner, M., Tolksdorf, K., Schueller, K., 2017, rriskDistributions_-Fitting distributions to given data or known quantiles: R package version 2.1.2, accessed June 24, 2020, at https://CRAN.R-project.org/package=rriskDistributions.

Bivand, R., and Rundel, C., 2019, rgeos - Interface to geometry engine-Open source ('GEOS'): R package version 0.5-1, accessed June 24, 2020, at https:/CRAN.Rproject.org/package $=$ rgeos.

Bromaghin, J.F., Douglas, D.C., Durner, G.M., Simac, K.S., and Atwood, T.C., 2020, Multistate capture and search data from the southern Beaufort Sea polar bear subpopulation in Alaska, 2001-2016: U.S. Geological Survey data release, https://doi.org/10.5066/P9A9E5UP. Bromaghin, J.F., McDonald, T.L., Stirling, I., Derocher, A.E., Richardson, E.S., Regehr, E.V., Douglas, D.C., Durner, G.M., Atwood, T.C., and Amstrup, S.C., 2015, Polar bear population dynamics in the southern Beaufort Sea during a period of sea ice decline: Ecological Applications, v. 25, p. 634-651.

Durner, G.M., Amstrup, S.C., Atwood, T.C., Douglas, D.C., Fischbach, A.S., Olson, J.W., Rode, K.D., and Wilson, R.R., 2020, Catalogue of polar bear (Ursus maritimus) maternal den locations in the Beaufort and Chukchi Seas and nearby areas, 1910-2018: U.S. Geological Survey Data Series 1121, accessed February 28, 2020, at https://doi.org/10.3133/ds1121. 
Fischbach, A.S., Amstrup, S.C., and Douglas, D.C., 2007, Landward and eastward shift of Alaskan polar bear denning associated with recent sea ice changes: Polar Biology, v. 30, p. 1395-1405.

Gelman, A., and Rubin, D.B., 1992, Inference from iterative simulation using multiple sequences: Statistical Science, v. 7, p. 457-511.

Horvitz, D.G., and Thompson, D.J., 1952, A generalization of sampling without replacement from a finite universe: Journal of the American Statistical Association, v. 47, p. 663-685. Intergovernmental Panel on Climate Change, 2019, Technical summary, in Pörtner, H.-O., Roberts, D.C., Masson-Delmotte, V., Zhai, P., Tignor, M., Poloczanska, E., Mintenbeck, K., Alegría, A., Nicolai, M., Okem, A., Petzold, J., Rama, B., and Weyer, N.M., eds., Special report on the ocean and cryosphere in a changing climate: Intergovernmental Panel on Climate Change, p. 39-69, accessed June 24, 2020, at https://www.ipcc.ch/srocc/.

International Union for Conservation of Nature Polar Bear Specialist Group, 2017, Status table for the world's polar bear subpopulations: International Union for Conservation of Nature/SSC Polar Bear Specialist Group, accessed June 24, 2020, at http://pbsg.npolar.no/en/.

Kellner, K., 2019, jagsUI-A wrapper around 'rjags' to streamline 'JAGS' analyses: R package version 1.5.1, accessed June 24, 2020, at https://CRAN.R-project.org/package=jagsUI.

Lebreton, J.-D., and Pradel, R., 2002, Multistate recapture models-Modelling incomplete individual histories: Journal of Applied Statistics, v., 29, p. 353-369.

McDonald, T.L., and Amstrup, S.C., 2001, Estimation of population size using open capturerecapture models: Journal of Agricultural, Biological, and Environmental Statistics, v. 6, p. 206-220.

Olson, J., Rode, K.D., Eggett, D., Smith, T.S., Wilson, R.R., Durner, G.M., Fischbach, A.S., Atwood, T.C., and Douglas, D.C., 2017, Identifying maternal denning of polar bears using temperature-Denning substrate in relation to sea ice in the southern Beaufort Sea: Marine Ecology Progress Series, v. 564, p. 211-224.

Plummer, M., 2012, JAGS version 3.2. 0 user manual, accessed June 24, 2020, at http://www.mas.ncl.ac.uk/ nmf16/teaching/mas8391/jags_user_manual.pdf.

Plummer, M., 2019, rjags_-Bayesian graphical models using MC̄MC: R package version 4-10, accessed June 24, 2020, at https://CRAN.R-project.org/package=rjags.

R Core Team, 2019, R-A language and environment for statistical computing: Vienna, Austria, R Foundation for Statistical Computing, accessed June 24, 2020, at https://www.Rproject.org/.

R Core Team, 2020, R-A language and environment for statistical computing: Vienna, Austria, R Foundation for Statistical Computing, accessed June 24, 2020, at: https://www.Rproject.org/.

Regehr, E.V., Hunter, C.M., Caswell, H., Amstrup, S.C., and Stirling, I., 2010, Survival and breeding of polar bears in the southern Beaufort Sea in relation to sea ice: Journal of Animal Ecology, v. 79, p. 117-127.

Rode, K.D., Amstrup, S.C., and Regehr, E.V., 2010, Reduced body size and cub recruitment in polar bears associated with sea ice decline: Ecological Applications, v. 20, p. 768-782.

Rode, K.D., Olson, J., Eggett, D., Douglas, D.C., Durner, G.M., Atwood, T.C., Wilson, R.R., Smith, T.S., and St. Martin, M., 2018, Den phenology and reproductive success of polar bears in a changing climate: Journal of Mammalogy, v. 99, p. 16-26. 
Schliebe, S., Rode, K.D., Gleason, J.S., Wilder, J., Proffitt, K., Evans, T.J., and Miller, S., 2008, Effects of sea-ice extent and food availability on spatial and temporal distribution of polar bears during the fall open-water period in the Southern Beaufort Sea: Polar Biology, v. 31, p. 999-1010.

Spiegelhalter, D.J., Best, N.G., Carlin, B.P., and van der Linde, A., 2014, The deviance information criterion-12 years on: Journal of the Royal Statistical Society, Series B, v. 76, p. 485-493.

U.S. Fish and Wildlife Service, 2016, Polar bear (Ursus maritimus) conservation management plan_Final: U.S. Fish and Wildlife Service, Region 7, Anchorage, Alaska, 104 p.

Wilson, R.R., and Durner, G.M., 2020, Seismic survey design and effects on maternal polar bear dens: Journal of Wildlife Management, v. 84, p. 201-212. 
Publishing support provided by the U.S. Geological Survey Science Publishing Network, Tacoma Publishing Service Center

For more information concerning the research in this report, contact the Director, Alaska Science Center

U.S. Geological Survey

4210 University Drive

Anchorage, Alaska 99508

https://www.usgs.gov/centers/asc/ 
